\title{
Model Struktur 1-D Kecepatan Gelombang $P$ di daerah Minahasa
}

\author{
Juan Pandu Gya Nur Rochman, Bagus Jaya Santosa,* dan Febry Rokhman Firdaus \\ Jurusan Fisika-FMIPA, Institut Teknologi Sepuluh Nopember \\ Kampus ITS Sukolilo, Surabaya 61111
}

\begin{abstract}
Intisari
Daerah Minahasa merupakan salah satu zona tektonik aktif di Indonesia karena memiliki zona sesar kompleks sebagai akibat pertemuan batas lempeng di barat laut pulau Sulawesi, sehingga sering terjadi gempa tektonik dangkal hingga sedang. Telah dilakukan studi spesifik mengenai struktur kecepatan gelombang gempa 1-D dan letak hypocenters yang lebih akurat di daerah Minahasa. Data yang digunakan sebanyak 8 event gempa di area sekitar Minahasa $\left(0,300^{\circ}-4,300^{\circ} \mathrm{LU}\right.$ dan $\left.121,0^{\circ}-121,7^{\circ} \mathrm{BT}\right)$ yang terjadi pada bulan Maret - Desember 2011 yang terekam di 8 stasiun seismograf setempat (KMSI, MRSI, MPSI, APSI, GLMI, LBMI, LUWI, dan SANI). Model struktur 1-D didapatkan dengan menganalisis waktu tempuh gelombang P dari data gempa lokal, yaitu dilakukan dengan picking menggunakan WinQuake. Data waktu tempuh gelombang P dilakukan inversi menggunakan software VELEST 33 sehingga didapatkan model struktur 1-D, kecepatan gelombang P dan relokasi gempa. Hasil pengelohan data didapatkan model struktur 1-D kecepatan gelombang P di daerah Minahasa berkisar antara $(2,95-9,07) \mathrm{km} / \mathrm{s}$ pada kedalaman $36 \mathrm{~km}$ dengan RMS residual = 3,7 dan didapatkan hypocenters baru yang lebih akurat.
\end{abstract}

KATA KUNCI: model kecepatan 1D, waktu tempuh gelombang P, WinQuake, VELEST 33

\section{PENDAHULUAN}

Indonesia merupakan daerah yang sangat berpotensi terjadinya gempa bumi, karena derah Indonesia terletak diantara 4 batas lempeng yaitu lempeng Australia, Filiphina, Pasifik, dan Asia kecil. Melihat tingginya aktifitas kegempaan, khususnya Badan Metereologi dan Klimatologi (BMKG) harus memiliki data yang memadai dan tepat tentang parameter hiposenter dari gempa untuk diinformasikan ke masyarakat luas. Parameter ini biasanya berupa magnitudo (kekuatan gempa), origin time (waktu terjadinya gempa), episenter (lokasi gempa), dan kedalaman pusat gempa. Ketelitian perhitungan parameter gempa sangat tergantung pada model struktur kecepatan gelombang gempa yang digunakan [1-3].

Di Indonesia model yang digunakan untuk menghitung parameter hiposenter gempa adalah model Jeffrey-Bullen [4]. Model struktur kecepatan tersebut dibuat dengan asumsi model bola bumi ideal. Model ini tentu saja tidak sesuai dengan kondisi wilayah kepulauan Indonesia yang mempunyai tatanan tektonik yang kompleks [5,6]. Oleh karena itu sangat mungkin menimbulkan kesalahan dalam perhitungan parameter hiposenter gempa.

Studi tentang model kecepatan 1-D ini dikembangkan oleh Kissling [7, 8]. Sotfware yang digunakan dalam menganalisa model kecepatan 1D ini dengan VELEST yang sudah terbukti bisa mendapatkan model kecepatan 1-D dengan baik [9-11]. Daerah Minahasa merupakan salah satu zona tektonik aktif di Indonesia karena memiliki zona sesar kompleks sebagai akibat pertemuan batas lempeng di barat laut pulau Sulawesi.

*E-MAIL: bjs@physics.its.ac.id

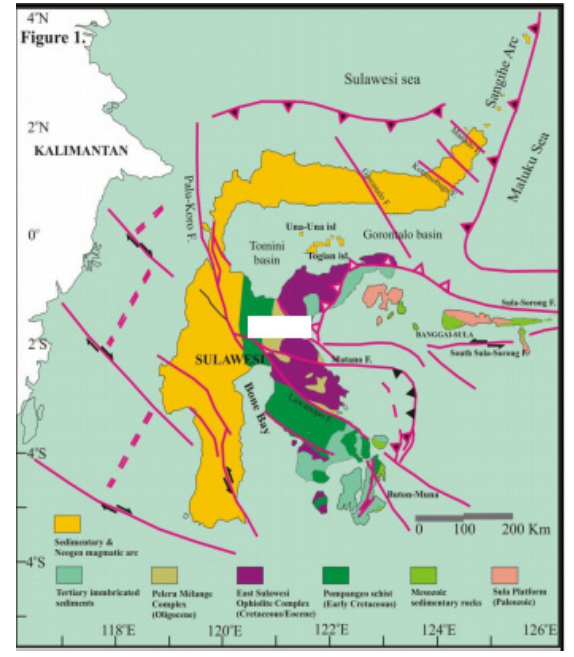

Gambar 1: Peta Tektonik Sulawesi [12].

Inilah yang menyebabkan minahasa sering terjadi gempa tektonik dangkal hingga sedang. Sehingga studi spesifik mengenai struktur kecepatan gelombang gempa 1-D penting dilakukan. Hasil studi ini juga diharapkan dapat memberikan informasi tambahan untuk penelitian lebih lanjut mengenai karakteristik struktur dangkal di daerah ini.

\section{LOKASI PENELITIAN DAN DATA GEMPA}

Lokasi penelitian ini berada di area sekitar Minahasa $\left(0,300^{\circ}-4,300^{\circ} \mathrm{LU}\right.$ dan $\left.121,0^{\circ}-121.7^{\circ} \mathrm{BT}\right)$, Sulawesi Utara. Daerah ini merupakan salah satu zona tektonik aktif di In- 

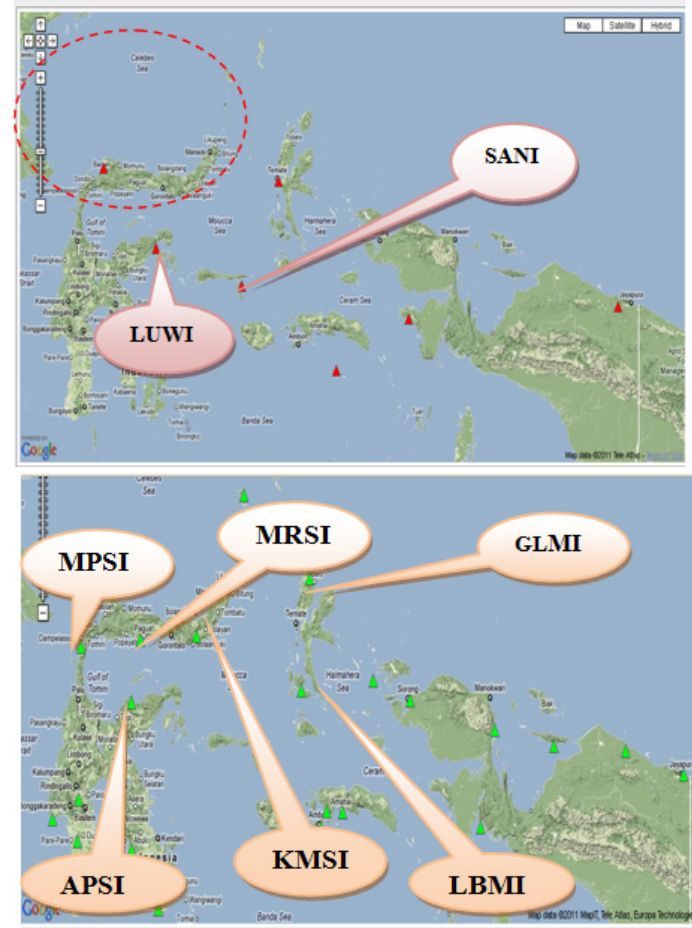

Gambar 2: Lokasi penelitian (lingkaran merah) dan jaringan stasiun. Titik panah orange menunjukkan letak stasiun seismograph jaringan kerjasama GFZ POSTDAM dengan BMKG di sekitar Minahasa.

donesia, karena daerah tersebut memiliki zona sesar kompleks sebagai akibat pertemuan batas lempeng di barat laut pulau Sulawesi (Gambar 1).

Data yang digunakan dalam studi ini adalah data waktu tempuh gelombang gempa yang didapatkan dari selisih antara waktu tiba gelombang $\mathrm{P}$ di stasiun-stasiun perekam dengan origin time dari gempa tersebut yang dapat didownload secara gratis di alamat http://webdc.eu/arclink/ query? sesskey $=45 c 89 b c f$.

Dalam kasus ini digunakan 8 event gempa di area seki$\operatorname{tar}$ Minahasa $\left(0,300^{\circ}-4,300^{\circ} \mathrm{LU}\right.$ dan $\left.121,0^{\circ}-121.7^{\circ} \mathrm{BT}\right)$ yang terjadi pada Maret 2011 - Desember 2011 dan terekam di jaringan seismograf kerjasama GFZ-POSTDAM dan BMKG sekitar Minahasa sebanyak 8 stasiun (Gambar 2). Untuk mengetahui model struktur kecepatan lokal, sehingga stasiun yang digunakan hanya yang berjarak kurang dari $800 \mathrm{~km}$ dari tempat kejadian gempa.

\section{HASIL DAN PEMBAHASAN}

Nilai gelombang $\mathrm{P}$ didapatkan dengan melakukan picking pada gelombang gempa dari masing-masing stasiun. Dalam penelitian ini dilakukan dengan menggunakan software WinQuake (Gambar 3), sehingga di dapatkan waktu tempuh gelombang P.

Model struktur 1-D kecepatan gelombang $\mathrm{P}$ didapatkan dengan melakukan inversi waktu tempuh gelombang $\mathrm{P}$ dengan menggunakan software VELEST. Diagram alir proses inversi

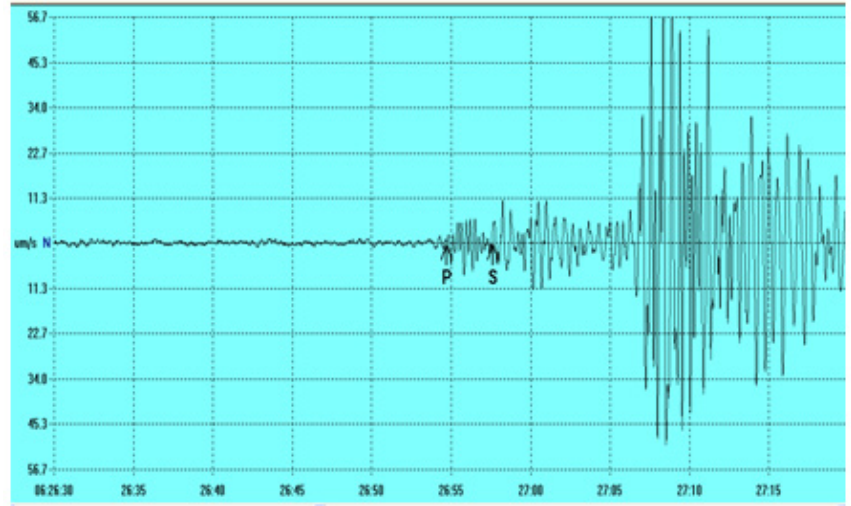

Gambar 3: Proses picking gelombang P dengan Sotfware WinQuake

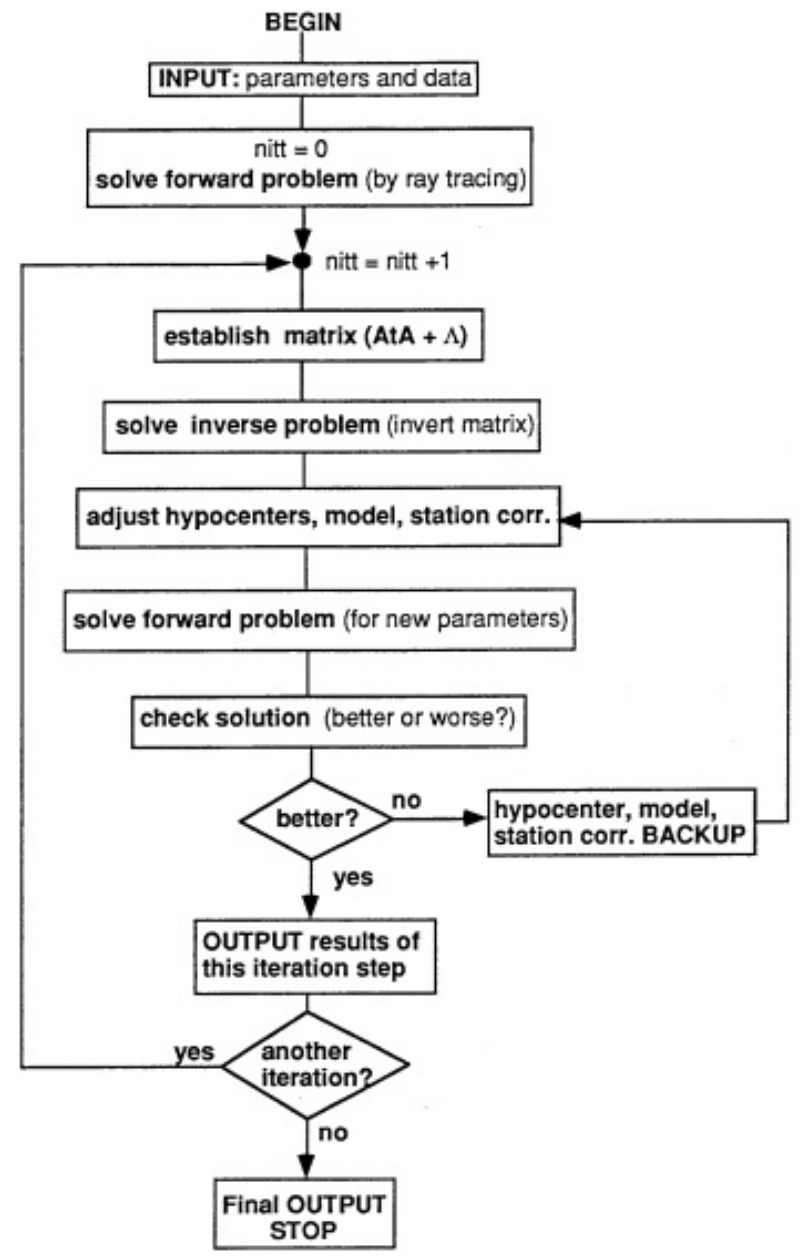

Gambar 4: Diagram alur proses software VELEST

software ini bisa dilihat pada Gambar 4.

Model struktur 1-D gelombang P dilihat pada Gambar 5. Hasil akhir perhitungan gempa ini dapat diamati bahwa model struktur 1-D kecepatan gelombang P di kerak bumi daerah Minahasa, Sulawesi utara adalah antara 2,95 km/s hingga 9,07 $\mathrm{km} / \mathrm{s}$ pada kedalaman $36 \mathrm{~km}$, dan terdapat Low Velocity Layer 
TABEL I: Model kecepatan gelombang P di tiap selang kedalaman hasil perhitungan program VELEST

\begin{tabular}{cc}
\hline \hline $\begin{array}{c}\text { Kedalaman } \\
(\mathrm{km})\end{array}$ & $\begin{array}{c}\text { Kecepatan Gel. P } \\
(\mathrm{km} / \mathrm{s})\end{array}$ \\
\hline $0,00-1,00$ & 3,28 \\
$1,00-3,00$ & 3,46 \\
$3,00-6,00$ & 3,18 \\
$6,00-10,00$ & 2,95 \\
$10,00-15,00$ & 5,59 \\
$15,00-20,00$ & 5,10 \\
$20,00-25,00$ & 6,68 \\
$25,00-30,00$ & 6,98 \\
$30,00-36,00$ & 9,07 \\
\hline \hline
\end{tabular}

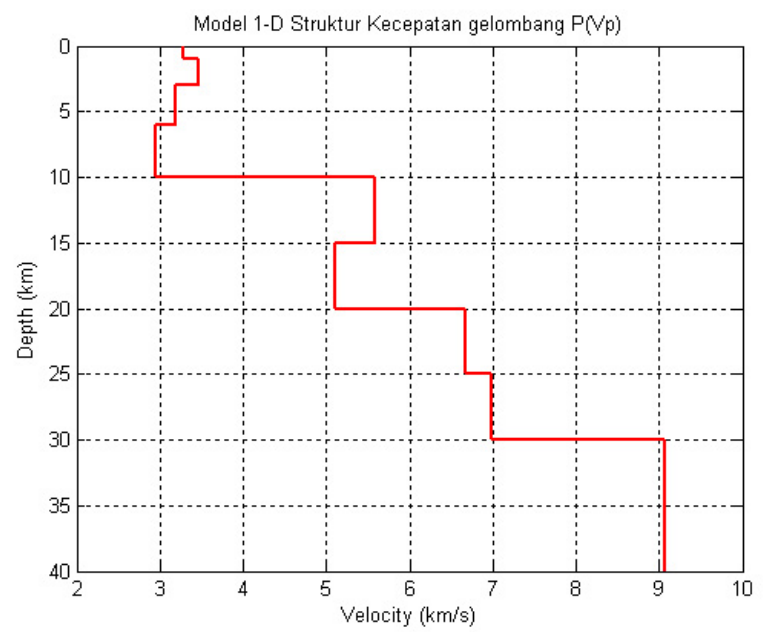

Gambar 5: Model struktur 1-D kecepatan gelombang P di kerak bumi daerah Minahasa berdasarkan data lokal.

(LVL) pada rentang kedalaman $(6-15) \mathrm{km}$.

Tabel II menunjukkan letak hypocenter awal. Dari VELEST juga di dapatkan letak hypocenter baru yang lebih tepat. Hasil dari hypocenter baru hasil perhitungan VELEST dapat dilihat pada Tabel III. Hasil plot dari letak hypocenter baru bisa dilihat pada Gambar 6 .

Proses perhitungan model struktur kecepatan gelombang $\mathrm{P}$ pada program VELEST dilakukan dengan memasukkan input model awal terlebih dahulu. Model inilah nanti yang akan di

TABEL II: Letak Hypocenter awal

\begin{tabular}{ccc}
\hline \hline $\mathrm{X}$ & $\mathrm{Y}$ & $\begin{array}{c}\mathrm{Z} \\
\text { (kedalaman) }\end{array}$ \\
\hline 384,11 & $-52,48$ & 86,00 \\
244,93 & 100,11 & 10,00 \\
82,43 & 80,21 & 26,00 \\
56,84 & $-61,32$ & 127,00 \\
11,20 & $-55,80$ & 127,00 \\
449,80 & $-125,46$ & 11,00 \\
52,39 & $-42,53$ & 164,00 \\
$-85,65$ & $-63,54$ & 46,00 \\
\hline \hline
\end{tabular}

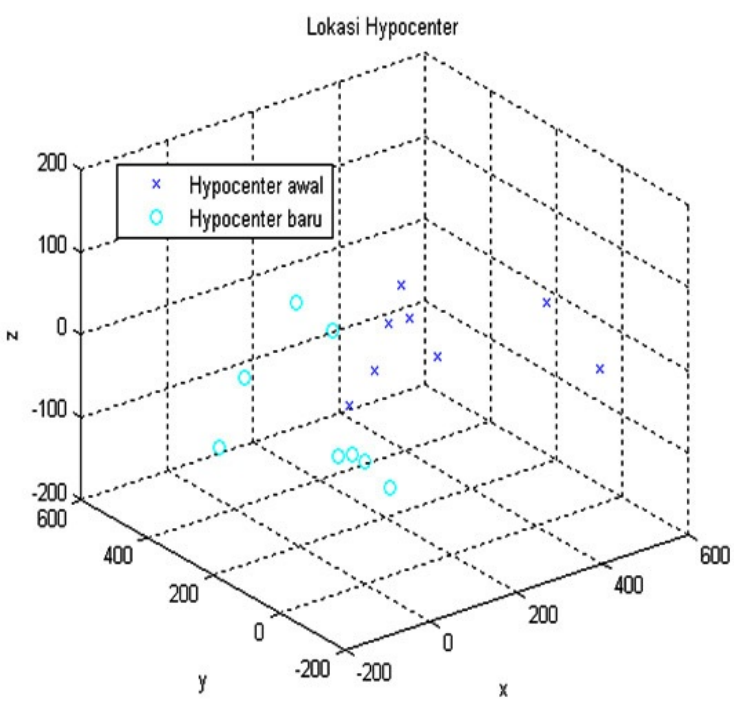

Gambar 6: Hypocenter baru hasil perhitungan VELEST.

TABEL III: Letak Hypocenter hasil dari VELEST

\begin{tabular}{ccc}
\hline \hline $\mathrm{X}$ & $\mathrm{Y}$ & $\begin{array}{c}\mathrm{Z} \\
\text { (kedalaman) }\end{array}$ \\
\hline 4,815 & 370,33 & $-35,99$ \\
4,728 & 214,60 & 91,45 \\
3,284 & 103,88 & 83,71 \\
4,760 & 87,85 & $-65,74$ \\
3,097 & 7,03 & $-53,51$ \\
2,877 & 445,05 & $-137,68$ \\
4,753 & 46,13 & $-53,33$ \\
3,166 & $-72,45$ & $-66,06$ \\
\hline \hline
\end{tabular}

hitung bersama dengan parameter-parameter even gempa dan stasiun perekam. Proses perhitungan bisa dilakukan dengan beberapa kali perulangan secara berkelanjutan (itterasi) untuk mendapatkan model dengan nilai RMS residual yang kecil.

Perhitungan untuk model kerak Minahasa ini dilakukan dengan iterasi sebanyak 9 kali. Hasil yang didapatkan sudah cukup bagus, yaitu model hasil perhitungan hanya memiliki RMS residual sebesar 3,7\% dan GAP 165. Hasil akhir perhitungan model kecepatan gelombang P tiap rentang kedalaman dapat dilihat pada Tabel I.

\section{SIMPULAN}

Model struktur 1-D kecepatan gelombang P di daerah Minahasa, Sulawesi Utara adalah antara 2,95 km/s hingga 9,07 $\mathrm{km} / \mathrm{s}$ pada kedalaman $36 \mathrm{~km}$ dengan RMS residual $=3,7$ dan GAP average 165 dan di dapatkan letak hypocenter baru yang lebih akurat. 
[1] R.S. Crosson, Journal Geophysical Research, 81, 4381 (1976).

[2] N.T. Puspito, Three-dimensional seismic velocity structure beneath the northern part of the Tohoku district, Honshu, Japan, Master Thesis, Horosaki University, 1990.

[3] T. Sato, Journal Physics of the Earth, 27, 239 (1979).

[4] H. Jeffrey, dan K.E. Bullen, Seismological Tables (British Association for the Advancement of Science, London, 1956).

[5] N.T. Puspito, et al., Tectonophysics, 220, 175 (1993).

[6] N.T. Puspito, Tecthonicphysics, 251, 215 (1995).

[7] E. Kisling, Rev.Geophysics., 26, 659 (1988).

[8] E. Kissling, Program VELEST User's Guide-Short Introduction (ETH Zuerich: Institute of Geophysics and Swiss Seismological
Service, 1995).

[9] W.L. Ellsworth, Three-dimensional structure of crust and mantle beneath the island of Hawaii, Ph.D. thesis, Massachusetts Institute of Technology, 1977.

[10] St. Roecker, Seismicity and Tectonics of the Pamer-hindu Kush region of central Asia, Ph.D. thesis, Massachusetts Institute of Technology, 1981.

[11] U. Kradofer, Seismiche Tomographie in der Sceiz mittels lokaler Erdbeben, Ph.D. thesis, ETH ZYrich, 109p, 1989.

[12] E.A. Silver, et al., Indonesia Jurnal Geophysicsal Research, 88(B11), p. 9419-9435 (1983). 